\title{
Biogas process parameters - energetics and kinetics of secondary fermentations in methanogenic biomass degradation
}

\author{
Dominik Montag ${ }^{1} \cdot$ Bernhard Schink $^{1}$
}

\begin{abstract}
Pool sizes of short-chain fatty acids (formate, acetate, propionate, and butyrate), hydrogen, and carbon monoxide were assayed in digesting sludge from four different methanogenic reactors degrading either sewage sludge or agricultural products and wastes at $\mathrm{pH} 8.0$ and 40 or $47{ }^{\circ} \mathrm{C}$. Free reaction energies were calculated for the respective degradation reactions involved, indicating that acetate, propionate, and butyrate degradation all supplied sufficient energy $(-10$ to $-30 \mathrm{~kJ}$ per mol reaction) to sustain the microbial communities involved in the respective processes. Pools of formate and hydrogen were energetically equivalent as electron carriers. In the sewage sludge reactor, homoacetogenic acetate formation from $\mathrm{H}_{2}$ and $\mathrm{CO}_{2}$ was energetically feasible whereas syntrophic acetate oxidation appeared to be possible in two biogas reactors, one operating at enhanced ammonia content (4.5 $\mathrm{g} \mathrm{NH}_{4}{ }^{+}$-N per 1) and the other one at enhanced temperature $\left(47^{\circ} \mathrm{C}\right)$. Maximum capacities for production of methanogenic substrates did not exceed the consumption capacities by hydrogenotrophic and aceticlastic methanogens. Nonetheless, the capacity for acetate degradation appeared to be a limiting factor especially in the reactor operating at enhanced ammonia concentration.
\end{abstract}

Keywords Methanogenesis · Energetics · Pool sizes · Fatty acids $\cdot$ Syntrophy $\cdot$ Secondary fermentations

Bernhard Schink

Bernhard.Schink@uni konstanz.de

1 Department of Biology, University of Konstanz, 78457 Konstanz, Germany

\section{Introduction}

Anaerobic decomposition of biomass in the absence of alternative electron acceptors leads to the production of methane and carbon dioxide in a process of at least three steps, including primary and secondary fermentations and finally methanogenesis. The overall process is found naturally in freshwater sediments and is being employed technically in biogas reactors and in anaerobic steps in wastewater treatment plants (Gujer and Zehnder 1983; Kaspar and Wuhrmann 1978). Biogas production can help to remove waste material, especially wastes of high water content that are not suited for incineration or pyrolysis, and provides a storable chemical energy carrier that can be applied also in a "power-ondemand" strategy in a network of renewable energy sources (Nationale Akademie der Wissenschaften L 2012).

To manage and secure stable and reliable process operation in biogas formation, the internal cooperation of the different functional groups (guilds) in biogas reactors has to be checked and maintained. For sufficient process monitoring, it is important to know which parameters are relevant, as well as their normal variation range and their impact on the overall system. Such parameters can be technical process parameters (Moestedt et al. 2014), e.g., the feed composition and the feeding rate, the operation temperature, the acidity or alkalinity, the activity of metabolites (concentration or partial pressure) (Ahring et al. 1995), the rates of microbially catalyzed reactions (Batstone et al. 2003), the composition of the microbial community (Ho et al. 2013), and many more.

In the complex metabolic network of the methanogenic feeding chain, almost every partial reaction can be ratelimiting for the overall process. The starting point, the hydrolysis of polymeric substrates, is always critical (Noike et al. 1985). But depending on the substrate feeding conditions, also the secondary fermenters (Palatsi et al. 2011) or either 
hydrogenotrophic or aceticlastic methanogens (Lü et al. 2013) can become bottlenecks in the overall process. Pool sizes of reaction intermediates may indicate where bottlenecks develop, i.e., where intermediates are produced faster than they are consumed. On the other hand, enhanced pool sizes provide more energy to the organism(s) degrading the respective intermediate and, with this, should increase the capacity for degradation of this intermediate by increasing the cell mass of the respective functional guild.

Since the reactions catalyzed by the last members in the feeding chain are often endergonic (Table 1) and the free energy available under in situ conditions is very limited, the pool sizes of the reaction intermediates determine which reactions are energetically feasible and can support microbial life. The quantitative relation between the flow of hydrogen, carbon dioxide, and acetate in syntrophic fatty acid oxidations is illustrated in Fig. S1 (suppl. material). For our calculations, we used $\Delta G^{\circ}$ values corrected for temperature $\left(40^{\circ} \mathrm{C}\right)$ as taken from Amend and Shock (2001) and interpolated the values between the temperature steps (see Table S1, suppl. material). Temperature effects are important especially in reactions involving gaseous reactants (i.e., rct. 3, 4, and 5 in Table 1), because of the large impact of entropy on gaseous compounds. This kind of calculation is closer to real conditions and could lead to new interpretations, especially if the reaction energy is close to the borderline between possible and impossible (e.g., acetate oxidation versus homoacetogenic fermentation; rct. 3 in Table 1).

Acetate and hydrogen typically contribute to methane formation at approximately a two-to-one ratio (Gujer and Zehnder 1983). This ratio may be shifted under specific conditions (enhanced temperature, high nitrogen loads) by homoacetogenesis (Ragsdale and Pierce 2008) or syntrophic acetate oxidation (Schnürer et al. 1996). This link could also be used as a side channel to the opposite side in case of a limitation or promotion of only one group of the methanogenic partners involved.

Several studies have dealt with the electron flow in methanogenic bioreactors in order to understand the complex interactions and limitations of the reaction steps involved (e.g., (McCarty and Smith 1986) and literature therein). In only few of these studies, hydrogen partial pressures could be measured with reliable methods (e.g., (Pauss et al. 1990)), and measurement of formate at micromolar concentrations was not possible at all so far. However, recent studies on the biochemistry of syntrophic oxidations (Müller et al. 2009; Müller et al. 2010; Schmidt et al. 2013; Worm et al. 2011) have shown that formate may be at least as important as hydrogen as an electron carrier between syntrophic partners. For a more exact assessment of the energetic situation of the various trophic groups within the biogas-forming community, we measured in the present study pool sizes of fatty acids including formate and of hydrogen and carbon monoxide at high sensitivity in digesting sludge from four different digesters operating at different rates with different feeds and efficiencies. Calculation of free energies of degradation of these reaction intermediates allows to identify bottlenecks in the overall transformation process, and measurement of degradation rates after substrate pulses allow to compare the actual substrate fluxes with their maximal capacities in the respective reactor systems. In contrast to previous studies (Kaspar and Wuhrmann 1978), here, the conversion rates are studied in batch culture in relatively short time periods to prevent adaptation of the community. A change of the community within a few hours is unlikely because of the long generation times of the target microorganisms.

\section{Materials and methods}

\section{Preparation and incubation of sludge samples}

Digesting sludges from the municipal wastewater treatment plant (WWTP) in Konstanz (Germany) and from three biogas reactors at Troisdorf (near Bonn, Germany) were sampled every other month over a total period of 2 years. The four fermenters were selected with respect to their operation strategies which differed in only one parameter. The digestion tower of the WWTP operated at $39^{\circ} \mathrm{C}$ and was fed a substrate mix (sewage sludge) typical of municipal wastewater treatment. BGR1 was a standard mesophilic biogas reactor $\left(40{ }^{\circ} \mathrm{C}\right)$ running at satisfying performance. BGR2 was a similar reactor $\left(40^{\circ} \mathrm{C}\right)$ with a higher load of ammonia-rich substrates and exhibited performance problems. BGR3 ran excellently at slightly enhanced temperature $\left(47^{\circ} \mathrm{C}\right)$. The substrate composition and other operating parameters for all four reactors are shown in Table 2. The sludge from the biogas reactors was shipped cooled at $4{ }^{\circ} \mathrm{C}$ for a maximum of 1 day before further processing. Before the main experiment, the sludge was incubated for 2 days at $40{ }^{\circ} \mathrm{C}$ to equilibrate. For better comparison, all incubation experiments were run at $40{ }^{\circ} \mathrm{C}$. The sludge was sieved through a 1-mm mesh size stainless steel sieve to obtain a homogenous dispersion and was distributed in aliquots of $50 \mathrm{ml}$ sludge in $150 \mathrm{ml}$ serum bottles under a headspace of $\mathrm{N}_{2} / \mathrm{CO}_{2}(80 / 20 \%)$.

\section{Analysis of pool sizes}

Gaseous compounds were analyzed by gas chromatography of headspace samples. $\mathrm{H}_{2}$ and $\mathrm{CO}$ were measured with a reductive gas chromatograph (Seiler et al. 1980) (peak performer 1, peak laboratories, Mountain View, CA). The system was equipped with an automatic sampling device (sample loop $100 \mu \mathrm{l}$ ) to enhance injection accuracy. Methane was measured with a gas chromatograph (Shimadzu GC-9A) equipped with a zeolite molecular sieve column and flame ionization 
Table 1 Syntrophic oxidation and methane formation reactions. $\Delta G$ values taken from Thauer et al. (1977) at $25^{\circ} \mathrm{C}$ and temperature corrected values as interpolated data from Amend and Shock (2001) at $40^{\circ} \mathrm{C}$

\begin{tabular}{llcc}
\hline No. & Equation & $\begin{array}{c}\Delta G^{\circ}\left[\mathrm{kJ} \mathrm{mol}{ }^{1}\right] \\
\text { at } 25^{\circ} \mathrm{C}\end{array}$ & $\begin{array}{c}\Delta G^{\circ}\left[\mathrm{kJ} \mathrm{mol}{ }^{1}\right] \\
\text { at } 40{ }^{\circ} \mathrm{C}\end{array}$ \\
\hline (1) & $\mathrm{CH}_{3} \mathrm{CH}_{2} \mathrm{CH}_{2} \mathrm{COO}+2 \mathrm{H}_{2} \mathrm{O} \rightarrow 2 \mathrm{CH}_{3} \mathrm{COO}+\mathrm{H}^{+} 2 \mathrm{H}_{2}$ & +48.3 & +47.0 \\
$(2)$ & $\mathrm{CH}_{3} \mathrm{CH}_{2} \mathrm{COO}+2 \mathrm{H}_{2} \mathrm{O} \rightarrow \mathrm{CH}_{3} \mathrm{COO}+\mathrm{CO}_{2}+3 \mathrm{H}_{2}$ & +71.7 & +67.2 \\
$(3)$ & $\mathrm{CH}_{3} \mathrm{COO}+\mathrm{H}^{+}+2 \mathrm{H}_{2} \mathrm{O} \rightarrow 2 \mathrm{CO}_{2}+4 \mathrm{H}_{2}$ & +94.9 & +84.7 \\
(4) & $\mathrm{CO}_{2}+4 \mathrm{H}_{2} \rightarrow \mathrm{CH}_{4}+2 \mathrm{H}_{2} \mathrm{O}$ & 130.8 & 124.6 \\
$(5)$ & $\mathrm{CH}_{3} \mathrm{COO}+\mathrm{H}^{+} \rightarrow \mathrm{CO}_{2}+\mathrm{CH}_{4}$ & 35.8 & 39.9 \\
(6) & $\mathrm{H}_{2}+\mathrm{CO}_{2} \rightarrow \mathrm{HCOO}^{+} \mathrm{H}^{+}$ & +3.5 & +6.7 \\
(7) & $\mathrm{CO}+\mathrm{H}_{2} \mathrm{O} \rightarrow \mathrm{H}_{2}+\mathrm{CO}_{2}$ & 20.0 & 21.1 \\
\hline
\end{tabular}

detector. $\mathrm{CO}_{2}$ partial pressure was not measured but calculated to be the remaining part of the atmosphere (together with methane).

Dissolved organic acids were measured by HPLC. Sludge samples were transferred into $50 \mathrm{ml}$ Falcon tubes and centrifuged at $5{ }^{\circ} \mathrm{C}$ for $10 \mathrm{~min}$ at $15,000 \mathrm{rpm}$. The supernatant was centrifuged again under the same conditions. The resulting supernatant was ultrafiltered using a 10-kDa Amicon ${ }^{\circledR}$ ultrafiltration device (10 $\mathrm{ml}$ per device). Ten microliters per milliliter of a $1 \mathrm{M} \mathrm{BaCl}_{2}$ stock solution was added to $1.5 \mathrm{ml}$ filtrate to precipitate anionic impurities (humic acids). The precipitation process was supported by freezing the sample in a freezer and melting during centrifugation at 15,000 rpm for $5 \mathrm{~min}$. One milliliter of the upper light fraction was taken for HPLC analysis. Short-chain fatty acids were quantified using a Shimadzu Prominence HPLC system equipped with an Aminex HPX87H column and a photo diode array detector. The separation conditions were $10 \mathrm{mM} \mathrm{H}_{3} \mathrm{PO}_{4}$ as isocratic eluent, $30 \mathrm{~min}$ analysis time, $50{ }^{\circ} \mathrm{C}$ column temperature, flow rate $1 \mathrm{ml}$ per min, UV channel at $200 \mathrm{~nm}$. This method allowed to analyze acid concentration in the range of 1$10 \mu \mathrm{M}$ of short-chain fatty acids, depending on the sample background. Every analysis cycle was followed by a cleaning step for fast elution of longer-chain fatty acids or other hydrophobic compounds.

\section{Calculation of Gibbs free energy of reactions}

Temperature-corrected standard Gibbs free energy of reactions were calculated from standard Gibbs free energies change of formation taken from (Amend and Shock 2001) at $40{ }^{\circ} \mathrm{C}$ by polynomic interpolation of the given data (Table 1 ; interpolation shown in supplemental materials). Measured pool sizes were used to calculate the Gibbs free energy of reactions via the Nernst equation. Volatile fatty acids were
Table 2 Technical process parameters and substrate composition

\begin{tabular}{|c|c|c|c|c|c|c|c|}
\hline \multirow[t]{2}{*}{ Sample taken } & WWTP & \multicolumn{2}{|c|}{ BGR 1} & \multicolumn{2}{|c|}{ BGR 2} & \multicolumn{2}{|c|}{ BGR 3} \\
\hline & 17.11.2014 & \multicolumn{2}{|c|}{ 12.01.2015 } & \multicolumn{2}{|c|}{21.01 .2015} & \multicolumn{2}{|c|}{04.02 .2015} \\
\hline Temperature $\left({ }^{\circ} \mathrm{C}\right)$ & 39 & 40 & & 40 & & 47 & \\
\hline Reactor size $\left(\mathrm{m}^{3}\right)$ & 4500 & 2800 & & 2500 & & 1650 & \\
\hline HRT (h) & 690 & 81 & & 86.2 & & 55 & \\
\hline Volume load (kg DM/m³ day) & 1.73 & 4.27 & & 4.11 & & 7.57 & \\
\hline Volume load (kg oDM/m³ day) & 1.44 & 3.93 & & 3.82 & & 6.47 & \\
\hline Biogas formation rate $\left(\mathrm{Nm}^{3} /\right.$ day $)$ & 3560 & 6373 & & 6024 & & 7680 & \\
\hline Methane formation rate $(\mathrm{mmol} / \mathrm{kg} \mathrm{h})$ & 0.831 & 1.92 & & 2.03 & & 3.92 & \\
\hline Substrates (t dry matter per day) & Sewage slud & & & & & & \\
\hline Maize silage & & 8.24 & $68.9 \%$ & 6.08 & $59.1 \%$ & 4.80 & $38.4 \%$ \\
\hline Green rye & & 0 & $0 \%$ & 0.96 & $9.3 \%$ & 2.24 & $17.9 \%$ \\
\hline Grain of wheat & & 0 & $0 \%$ & 0 & $0 \%$ & 3.48 & $27.9 \%$ \\
\hline Cow manure & & 2.36 & $19.8 \%$ & 0.26 & $2.6 \%$ & 0 & $0 \%$ \\
\hline Cattle slurry & & 0 & $0 \%$ & 0.12 & $1.2 \%$ & 0.88 & $7.0 \%$ \\
\hline Horse manure & & 0 & $0 \%$ & 0.27 & $2.6 \%$ & 1.09 & $8.7 \%$ \\
\hline Dried chicken feces & & 1.35 & $11.3 \%$ & 2.59 & $25.2 \%$ & 0 & $0 \%$ \\
\hline $\mathrm{NH}_{4}$ nitrogen & 1.1 & 3.1 & & 4.5 & & 1.5 & \\
\hline
\end{tabular}

HRT hydraulic retention time, $D M$ dry matter, $o D M$ organic dry matter, $N m^{3}$ normal $\mathrm{m}^{3}$ (at 1 atm) 
used as molar concentrations and $\mathrm{H}_{2}, \mathrm{CH}_{4}$, and $\mathrm{CO}_{2}$ as partial pressures in the headspace.

\section{Analysis of maximal turnover rates}

For estimation of maximal turnover rates $\left(v_{\max }\right)$, pulses of specific substrates $(50 \mathrm{mM}$ acetate, $15 \mathrm{mM}$ propionate or butyrate) were injected from stock solutions and degradation was followed, taking samples at defined time points (before addition, after addition/time $=0 \mathrm{~h}$, and at 8, 24, and $29 \mathrm{~h}$ ). Every time point and substrate variant was done in triplicate as deadend replicates. Degradation rates were calculated from initial concentration decreases and related to $1 \mathrm{~g}$ sludge (wet weight) and $1 \mathrm{~h}$. Acetate degradation was measured at an overpressure of hydrogen ( 1 bar, $\mathrm{H}_{2} / \mathrm{CO}_{2}, 80 \% / 20 \%$ ) in the headspace to inhibit syntrophic oxidation reactions. The rate of maximal hydrogenotrophic methanogenesis was calculated as the difference between the rate of overall methane formation and the acetate consumption rate. The rate of maximal butyrate and propionate oxidation was used to calculate the specific rates of acetate and hydrogen production from these reactions. Comparison of methanogenic substrate production and consumption allowed to estimate the metabolic capacity for every compound.

\section{Results}

\section{Pool sizes}

Pool sizes of formate, acetate, propionate, and butyrate were determined in the liquid phase of all four reactor sludges (Table 3). The values given are representative of more than 10 values determined for every reactor through the entire sampling period. Determined values differed by less than $10 \%$ between samples taken from the same reactor at different times but differed significantly between the different reactors. Acetate concentrations differed by three orders of magnitude $(10 \mu \mathrm{M}$ to $10 \mathrm{mM})$, propionate within two orders of magnitude, and butyrate from non-detectable $(<1 \mu \mathrm{M})$ in samples from BGR1 and the WWTP to $0.6 \mathrm{mM}$ in BGR2. In general, these three fatty acids varied in a more or less parallel manner between the different reactors, with low values in WWTP and BGR1 and higher values in BGR2 and BGR3. Formate concentrations are being documented in this study for the first time because formate is difficult to assess at micromolar concentrations in sludge samples containing high backgrounds of complex organics, esp. humic compounds. We developed a specific assay protocol that is described in the "Materials and methods" section. Measured formate concentrations in the sludge varied between 1 and $15 \mu \mathrm{M}$, roughly in parallel with the hydrogen partial pressures in the headspace (10-45 ppm, equal to $1-4.5 \mathrm{~Pa}$ ). Carbon monoxide was measured to investigate a possible relationship to reactions involving carbon monoxide dehydrogenase, e.g., homoacetogenic fermentation and acetate cleavage reactions.

The methane concentration in the headspace is determined by the redox state of the reactor feed. The Buswell equation (Buswell and Mueller 1952) allows to calculate the ratio of methane and carbon dioxide in the resulting biogas. While the WWTP digested primarily microbial biomass, i.e., membrane lipids and proteins, the biogas reactors were fed mainly carbohydrates and animal wastes (see Table 2). The substrate composition is also responsible for the acidity of the sludge. The fermented plant materials and ammonia-rich substrates buffered the biogas sludge at a slightly higher $\mathrm{pH}$ value than the digested sludge from the WWTP.

\section{Energetics of in situ metabolite transformations}

Gibbs' free energy changes were calculated for transformation reactions between metabolites at the measured pool sizes for every reactor under study. The reaction energy of butyrate oxidation was similar in all samples, around $-24 \mathrm{~kJ}$ per mol (Table 4); for the samples of WWTP and BGR1, we assumed butyrate concentrations below the detection limit to allow estimates of energy changes. For propionate oxidation, the calculated values were between -10.9 and $-19.3 \mathrm{~kJ}$ per mol. $\Delta G$ values for aceticlastic methanogenesis were between -13.9 and $-23.5 \mathrm{~kJ}$ per mol and for hydrogenotrophic methanogenesis between -5.6 and $-18.8 \mathrm{~kJ}$ per mol. The calculated Gibbs' free energy values of acetate oxidation were between +9.5 and $-9.6 \mathrm{~kJ}$ per mol, indicating that the reaction may run towards acetate formation in the WWTP reactor and towards acetate oxidation in the reactors BGR2 and BGR3.

Conversions of formate to $\mathrm{H}_{2}+\mathrm{CO}_{2}$ and vice versa were weakly exergonic in either direction. The ratios of the formate and the hydrogen pool showed a weak linear dependency of $0.31 \mathrm{~mol}$ formate per $\mathrm{mol} \mathrm{H}_{2}$. The averaged reaction energy for this conversion was calculated as $-0.5 \mathrm{~kJ}$ per mol hydrogen. Conversion of $\mathrm{CO}$ to $\mathrm{H}_{2}+\mathrm{CO}_{2}$ was exergonic in all reactors, with a $\Delta G$ at about $-20 \mathrm{~kJ}$ per mol.

\section{Pool size enlargements and turnover rates of specific metabolites}

Maximal turnover capacities were examined for the key intermediates butyrate, propionate, and acetate by measuring pool size decreases after injecting pulses of the respective substrates (Table 5). Maximal rates of acetate production through these processes did not exceed significantly the capacities for acetate consumption by the methanogens in WWTP, BGR1, and BGR2 (107, 119, and $65 \%$ ). Only in BGR3 a twofold higher production than consumption capacity was found (193\%). The maximum capacities of hydrogenotrophic and acetotrophic methanogenesis together were in the same range 
Table 3 Pool sizes of fatty acids and other parameters measured in samples from a wastewater treatment plant (WWTP) and three biogas reactors (BGR1 3)

\begin{tabular}{lllll}
\hline Compound & WWTP & BGR1 & BGR2 & BGR3 \\
\hline Formate $\left(\mathrm{mmol} \mathrm{l}^{1}\right.$ ) & $0.015 \pm 0.000$ & $0.001 \pm 0.001$ & $0.011 \pm 0.002$ & $0.001 \pm 0.000$ \\
Acetate $\left(\mathrm{mmol} \mathrm{l}^{1}\right.$ ) & $0.010 \pm 0.001$ & $0.180 \pm 0.012$ & $10.103 \pm 0.703$ & $0.948 \pm 0.057$ \\
\left.${\text { Propionate }\left(\mathrm{mmol}^{1}\right)}^{1}\right)$ & $0.078 \pm 0.005$ & $0.016 \pm 0.005$ & $1.315 \pm 0.156$ & $0.097 \pm 0.015$ \\
Butyrate $\left(\mathrm{mmol} \mathrm{l}^{1}\right)$ & $<0.001$ & $<0.001$ & $0.597 \pm 0.042$ & $0.034 \pm 0.002$ \\
$\mathrm{pH}$ & 7.4 & 8.2 & 8.3 & 8.1 \\
Hydrogen (ppm) & $44.7 \pm 0.5$ & $18.2 \pm 0.7$ & $29.1 \pm 0.2$ & $10.9 \pm 0.7$ \\
Carbon monoxide (ppm) & $18.0 \pm 0.2$ & $17.7 \pm 0.5$ & $10.2 \pm 0.1$ & $1.8 \pm 0.3$ \\
Methane (bar) & $0.67 \pm 0.02$ & $0.55 \pm 0.01$ & $0.50 \pm 0.02$ & $0.50 \pm 0.01$ \\
\hline
\end{tabular}

as the in situ methane production performances of the respective reactors (Table 2).

\section{Discussion}

Transformation of biomass to methane and $\mathrm{CO}_{2}$ requires an efficient transfer of reaction intermediates between primary fermentations, secondary fermentations, and methanogenesis. The available energy under in situ conditions depends strongly on the pool sizes of the reaction intermediates; these pool sizes determine whether such conversions are energetically possible and, if so, whether they release sufficient energy for ATP generation by the organisms involved. In the present study, we measured pool sizes of the key fermentation intermediates acetate, propionate, and butyrate. For the first time, we also included measurements of formate, together with assays of hydrogen and carbon monoxide concentrations in the headspace. Whereas pool sizes of short-chain fatty acids have been reported repeatedly in the past and have been used as indicators of reactor stability and efficiency (Gujer and Zehnder 1983), an assessment of the energetic situation especially of the secondary fermenters in the system requires measurement also of hydrogen and formate which are considered as important co-products of secondary fermentations (Schink 1997). Since the redox potential of the $\mathrm{H}^{+} / \mathrm{H}_{2}$ pair and the $\mathrm{CO}_{2}$ /formate pair at pH 7.0 are nearly identical $\left(E_{0}{ }^{\prime}=-414\right.$ vs. $-430 \mathrm{mV}$ ) and most methanogenic partners can use both hydrogen and formate as electron donors, it has remained a matter of discussion whether actually hydrogen or formate is the electron carrier between secondary fermenters and their methanogenic partners (Bryant et al. 1967; McInerney et al. 1979). Recent evidence obtained in biochemical, genomic, and proteomic studies of secondary fermenters indicates that formate may be at least as important as hydrogen in interspecies electron transfer (Müller et al. 2009; Müller et al. 2010; Schmidt et al. 2013; Worm et al. 2011). We therefore included measurement of formate pool sizes in the present study.

According to our results, formate and hydrogen pools, although varying between the different reactors studied, remained in a more or less stable ratio to each other and were energetically equivalent with respect to their formation and degradation. Thus, both carriers may be used for interspecies electron transfer at a similar redox potential and they may even be used simultaneously. Actually, several formate hydrogen lyases have been described recently in strictly anaerobic bacteria (Schmidt et al. 2013; Schuchmann and Müller 2014) which, if present at sufficient activity, should equilibrate these two pools in anoxic environments such as biogas sludge.

The redox potential of the $\mathrm{CO}_{2} / \mathrm{CO}$ couple $\left(E_{0}{ }^{\prime}=-520 \mathrm{mV}\right)$ is by about $100 \mathrm{mV}$ lower than that of the $\mathrm{CO}_{2}$ /formate and the $\mathrm{H}^{+} / \mathrm{H}_{2}$ pool, providing an energy potential of roughly $-20 \mathrm{~kJ}$ per mol towards hydrogen formation. In our measurements, the hydrogen and the $\mathrm{CO}$ pool were at similar orders of magnitude
Table 4 Gibbs' free energy changes of conversion reactions in equilibrated digested sludge systems (waste water treatment plant and biogas reactors); the complete conversion reactions are given in Table 1

\begin{tabular}{lccccc}
\hline Step & Eq.no. & $\begin{array}{l}\text { WWTP } \\
\left(\mathrm{kJ} \mathrm{mol}^{1}\right)\end{array}$ & $\begin{array}{l}\text { BGR1 } \\
\left(\mathrm{kJ} \mathrm{mol}^{1}\right)\end{array}$ & $\begin{array}{l}\text { BGR2 } \\
\left(\mathrm{kJ} \mathrm{mol}{ }^{1}\right)\end{array}$ & $\begin{array}{l}\text { BGR3 } \\
\left(\mathrm{kJ} \mathrm{mol}{ }^{1}\right)\end{array}$ \\
\hline Butyrate oxidation & $(1)$ & $21.4^{*}$ & $20.0^{*}$ & 20.0 & 28.6 \\
Propionate oxidation & $(2)$ & 19.3 & 13.8 & 10.9 & 17.9 \\
Acetate oxidation & $(3)$ & +8.8 & 3.5 & 7.7 & 13.2 \\
$\mathrm{H}_{2}$ to $\mathrm{CH}_{4}$ & $(4)$ & 9.6 & 10.4 & 15.8 & 5.6 \\
Acetate to $\mathrm{CH}_{4}$ & $(5)$ & 18.4 & 13.9 & 23.5 & 18.8 \\
Formate to $\mathrm{H}_{2}+\mathrm{CO}_{2}$ & $(6)$ & +2.6 & 5.9 & 2.0 & 4.3 \\
$\mathrm{CO}$ to $\mathrm{H}_{2}+\mathrm{CO}_{2}$ & $(7)$ & 21.7 & 23.2 & 20.2 & 18.3 \\
\hline
\end{tabular}

*Calculation based on estimated butyrate concentrations below the detection limit: WWTP 10 nM and BGR1 100 $\mathrm{nM}$ 
Table 5 Turnover rates of specific metabolites

\begin{tabular}{lllll}
\hline Step (equation) & $\begin{array}{l}\text { WWTP } \\
\left(\mu \mathrm{mol}(\mathrm{g} \mathrm{h})^{1}\right)\end{array}$ & $\begin{array}{l}\text { BGR1 } \\
\left(\mu \mathrm{mol}(\mathrm{g} \mathrm{h})^{1}\right)\end{array}$ & $\begin{array}{l}\text { BGR2 } \\
\left(\mu \mathrm{mol}(\mathrm{g} \mathrm{h})^{1}\right)\end{array}$ & $\begin{array}{l}\text { BGR3 } \\
\left(\mu \mathrm{mol}(\mathrm{g} \mathrm{h})^{1}\right)\end{array}$ \\
\hline Butyrate oxidation (1) & $0.48 \pm 0.02$ & $0.38 \pm 0.02$ & $0.08 \pm 0.02$ & $0.80 \pm 0.02$ \\
Propionate oxidation (2) & $0.20 \pm 0.04$ & $0.43 \pm 0.04$ & $0.18 \pm 0.05$ & $0.62 \pm 0.03$ \\
Syntrophic hydrogen production & $1.56 \pm 0.12$ & $2.05 \pm 0.16$ & $0.70 \pm 0.19$ & $3.46 \pm 0.13$ \\
Hydrogenotrophic $\mathrm{CH}_{4}$ equivalents (4) & $0.39 \pm 0.03$ & $0.51 \pm 0.04$ & $0.18 \pm 0.05$ & $0.87 \pm 0.03$ \\
Syntrophic acetate production & $1.16 \pm 0.08$ & $1.19 \pm 0.08$ & $0.34 \pm 0.09$ & $2.22 \pm 0.07$ \\
Hydrogenotrophic methanogenesis (4) & $0.68 \pm 0.18$ & $2.05 \pm 0.03$ & $0.18 \pm 0.10$ & $1.59 \pm 0.02$ \\
Aceticlastic methanogenesis (5) & $1.08 \pm 0.18$ & $1.00 \pm 0.03$ & $0.52 \pm 0.10$ & $1.15 \pm 0.02$ \\
Methane formation (max.) & $1.76 \pm 0.07$ & $3.05 \pm 0.13$ & $0.75 \pm 0.04$ & $2.77 \pm 0.04$ \\
\hline
\end{tabular}

Syntrophic conversion rates were calculated from butyrate and propionate consumption rate; units in micromole substrate per hour and gram sludge; hydrogenotrophic substrate $=\mathrm{CO}_{2}$, see Eq. $4 ; \pm$ standard deviation and the mentioned energy potential was maintained. Obviously, $\mathrm{CO}$ electrons and electrons of the hydrogen/formate pool were not equilibrated but existed in separate pools. The $\mathrm{CO}$ pool may be associated with the nickel centers of $\mathrm{CO}$ dehydrogenase/ acetate synthase that is essential in homoacetogenic acetate formation and syntrophic or aceticlastic acetate degradation (Can et al. 2014) and is not used for interspecies electron transfer. Whether the CO pool can be taken as a measure of CO dehydrogenase activity remains an open question. In our assays, we could not find an obvious relationship between the $\mathrm{CO}$ pool and the expected activities: the lowest $\mathrm{CO}$ pool was found in the BGR3 sample where acetate oxidation was energetically possible, and the highest concentration was found in the WWTP where homoacetogenesis was possible.

Although the pool sizes of acetate, propionate, and butyrate varied substantially between the four reactors studied, they appeared to vary more or less in parallel, with low values in the well-performing biogas reactors 1 and 3 and the waste water treatment plant, as opposed to the less efficiently operating biogas reactor 2 which exhibited concentrations of acetate, propionate, and butyrate more than 10 times as high as in the other reactors. Obviously, the insufficient performance of biogas reactor 2 was associated with the accumulation of short-chain fatty acids. Since the $\mathrm{pH}$ in all reactors was slightly alkaline, we can assume that fatty acids in the concentration range measured in reactor 2 did not become toxic and that the fatty acid accumulation was a symptom rather than the reason of low performance of this reactor.

The measured pool sizes allowed to calculate the free energy changes of the secondary fermenting and the methanogenic reactions during methanogenesis, as listed in Tables 1 and 4. Syntrophic oxidation of butyrate and propionate (equation 1 and 2) as well as hydrogen-dependent methane formation and acetate conversion to methane yielded in nearly all cases free energy changes in the range between -10 and $-20 \mathrm{~kJ}$ per mol reaction and beyond. Acetate oxidation to $\mathrm{H}_{2}+\mathrm{CO}_{2}$ (equation 3) was weakly endergonic in biogas reactor 1 but could release reasonable amounts of energy in reactors 2 and 3. At enhanced temperature, the acetate oxidation process was reported to be more likely (Hao et al. 2010). This was obviously true for our thermal reactor BGR3 where enhanced acetate degradation (by oxidation and aceticlastic methanogenesis) also stimulated the activities of the acetateproducing guilds (butyrate and propionate degradation rate; Table 5, BGR3). After adjustment to $40{ }^{\circ} \mathrm{C}$, the flux through acetate oxidation was no longer promoted and the overall methane formation rate dropped to about $50 \%$ of the in situ activity. In the WWTP reactor, the reaction was exergonic in the opposite direction, i.e., towards homoacetogenic fermentation. To which extent syntrophic acetate oxidation or homoacetogenic fermentation really occurred in our reactors remains open. So far, syntrophic acetate oxidation has been documented to dominate acetate metabolism at enhanced temperature $\left(\geq 55^{\circ} \mathrm{C}\right.$; (Zinder and Koch 1984)) or in the presence of ammonia at a high concentration which obviously inhibits aceticlastic methanogenesis (Schnürer et al. 1994). Since ammonia concentrations in our biogas reactors were comparably high, especially in the ill-performing biogas reactor 2, syntrophic acetate oxidation may indeed contribute to acetate metabolism also in this reactor.

Are the energy gains calculated for these reactors sufficient to sustain microbial growth? In an earlier review, it was postulated that at least $-20 \mathrm{~kJ}$ per mol reaction should be available to synthesize ATP at minimal increments (Schink 1997). Later, we corrected this value to -12 to $-15 \mathrm{~kJ}$ per mol reaction, based on new insights into the stoichiometry of the ATPase reactions and considerations on the energy charge of syntrophically fermenting bacteria (Schink and Stams 2013). Energy gains in this range were reported before for syntrophic oxidation of butyrate (Adams et al. 2006; Wang et al. 2013), propionate (Krylova and Conrad 1998; Scholten and Conrad 2000), and acetate (Hao et al. 2010; Schnürer et al. 1997), as well as for homoacetogenic fermentation (Conrad and Wetter 1990; Fey and Conrad 2000; Seitz et al. 1990), aceticlastic methanogenesis (Fey and Conrad 2000; Penning and Conrad 2006), and hydrogen-dependent methanogenesis (Dwyer et al. 1988; Seitz 
et al. 1990). (Hoehler et al. 2001) calculated energy gains in the range from -10 to $-19 \mathrm{~kJ}$ per mol reaction for syntrophically cooperating partners in sediments. Extremely low energy charges under starvation, and employment of, e.g., electrogenic sodium/proton antiporters, may decrease the minimum amount of energy needed to sustain life even further (Müller 2015; Spahn et al. 2015, Lim et al. 2014). In any case, we have to keep in mind that measurements of bulk concentrations both in the gas phase and in the liquid phase give only a rough estimate of the actual in situ concentrations of the intermediates within the microstructure of microbial aggregates (Pauss et al. 1990). For the processes occurring in biogas reactors where the microbial communities have to keep up with hydraulic retention times (i.e., doubling times) of 1-3 weeks, it appears reasonable to predict that a sufficient energy charge for growth can be maintained with energy gains at minimum $-12 \mathrm{~kJ}$ per mol reaction, keeping in mind that in some cases mixed-substrate supply situations may even improve the energetic situation of a single organism. The latter aspect may be of interest especially for metabolically versatile organisms such as homoacetogens which can also ferment methyl residues and sugars.

Our measurements of maximum substrate turnover capacities (Table 5) indicate that the capacities for butyrate and propionate turnover were well within the limits of the total methane formation capacities in the respective reactors. In biogas reactor 3 , the syntrophic fatty acid degradation capacities exceeded the capacity for aceticlastic methanogenesis substantially, showing that this well-performing reactor operating at enhanced temperature had sufficient capacities to deal with occasional fatty acid pulses. The same reactor showed as well that both hydrogenotrophic and aceticlastic methanogenesis can become limiting for the overall process. The less efficiently performing biogas reactor 2 exhibited the lowest capacities in both methane formation reactions, indicating that in this case the terminal steps slowed down the overall degradation process. One has to keep in mind that a major part of hydrogen and acetate supply for methanogenesis comes from the primary fermentation processes, the activities of which we could not quantify in our experimental setup.

Acknowledgments The authors are grateful to Melanie Hecht, Thomas Dickhaus, and Sarah Refai for organizing the sampling campaigns at the biogas reactors at Troisdorf and to Erich Kronenthaler and Martin Kaspar for the supply of sewage sludge and operation parameters of the reactor at the wastewater treatment plant in Konstanz. The technical help with spe cific experiments in the lab by Antje Wiese, Ye Schmidt, and Stefan Bieletzki is highly appreciated.

\section{Compliance with ethical standards}

Funding This study was funded by the German Federal Ministry for Education and Research, project BioPara, project number 03SF0421E.

Conflict of interest The authors declare that they have no competing interests.
Ethical approval This article does not contain any studies with human participants or animals performed by any of the authors.

\section{References}

Adams CJ, Redmond MC, Valentine DL (2006) Pure culture growth of fermentative bacteria, facilitated by $\mathrm{H}_{2}$ removal: bioenergetics and $\mathrm{H}_{2}$ production. Appl Environ Microbiol 72(2):1079 1085

Ahring BK, Sandberg M, Angelidaki I (1995) Volatile fatty acids as indicators of process imbalance in anaerobic digestors. Appl Microbiol Biotechnol 43(3):559 565

Amend JP, Shock EL (2001) Energetics of overall metabolic reactions of thermophilic and hyperthermophilic Archaea and bacteria. FEMS Microbiol Rev 25(2):175 243

Batstone DJ, Pind PF, Angelidaki I (2003) Kinetics of thermophilic, an aerobic oxidation of straight and branched chain butyrate and valer ate. Biotechnol Bioeng 84(2):195 204

Bryant M, Wolin E, Wolin M, Wolfe R (1967) Methanobacillus omelianskii, a symbiotic association of two species of bacteria. Arch Mikrobiol 59(1 3):20 31

Buswell A, Mueller H (1952) Mechanism of methane fermentation. Industrial \& Engineering Chemistry 44(3):550 552

Can M, Armstrong FA, Ragsdale SW (2014) Structure, function, and mechanism of the nickel metalloenzymes, $\mathrm{CO}$ dehydrogenase, and acetyl CoA synthase. Chem Rev 114(8):4149 4174

Conrad R, Wetter B (1990) Influence of temperature on energetics of hydrogen metabolism in homoacetogenic, methanogenic, and other anaerobic bacteria. Arch Microbiol 155(1):94 98

Dwyer DF, Weeg Aerssens E, Shelton DR, Tiedje JM (1988) Bioenergetic conditions of butyrate metabolism by a syntrophic, anaerobic bacterium in coculture with hydrogen oxidizing methan ogenic and sulfidogenic bacteria. Appl Environ Microbiol 54(6): 13541359

Fey A, Conrad R (2000) Effect of temperature on carbon and electron flow and on the archaeal community in methanogenic rice field soil. Appl Environ Microbiol 66(11):4790 4797

Gujer W, Zehnder A (1983) Conversion processes in anaerobic digestion. Water Science \& Technology 15(8 9):127 167

Hao L P, Lü F, He P J, Li L, Shao L M (2010) Predominant contribution of syntrophic acetate oxidation to thermophilic methane formation at high acetate concentrations. Environmental Science \& Technology 45(2):508 513

Ho DP, Jensen PD, Batstone DJ (2013) Methanosarcinaceae and acetate oxidizing pathways dominate in high rate thermophilic anaerobic digestion of waste activated sludge. Appl Environ Microbiol 79(20):6491 6500

Hoehler TM, Alperin MJ, Albert DB, Martens CS (2001) Apparent min imum free energy requirements for methanogenic Archaea and sulfate reducing bacteria in an anoxic marine sediment. FEMS Microbiol Ecol 38(1):33 41

Kaspar HF, Wuhrmann K (1978) Kinetic parameters and relative turn overs of some important catabolic reactions in digesting sludge. Appl Environ Microbiol 36(1):1 7

Krylova NI, Conrad R (1998) Thermodynamics of propionate degrada tion in methanogenic paddy soil. FEMS Microbiol Ecol 26(4):281 288

Lim JK, Mayer F, Kang SG, Müller V (2014) Energy conservation by oxidation of formate to carbon dioxide and hydrogen via a sodium ion current in a hyperthermophilic archaeon. Proc Natl Acad Sci 111(31):11497 11502 
Lü F, Hao L, Guan D, Qi Y, Shao L, He P (2013) Synergetic stress of acids and ammonium on the shift in the methanogenic pathways during thermophilic anaerobic digestion of organics. Water Res 47(7):2297 2306

McCarty PL, Smith DP (1986) Anaerobic Waste Water Treatment. 4. Environmental Science \& Technology 20(12):1200 1206. doi:10. 1021/es00154a002

McInerney MJ, Bryant MP, Pfennig N (1979) Anaerobic bacterium that degrades fatty acids in syntrophic association with methanogens. Arch Microbiol 122(2):129 135

Moestedt J, Nordell E, Schnürer A (2014) Comparison of operating strat egies for increased biogas production from thin stillage. J Biotechnol 175:22 30

Müller N, Schleheck D, Schink B (2009) Involvement of NADH: accep tor oxidoreductase and butyryl coenzyme A dehydrogenase in re versed electron transport during syntrophic butyrate oxidation by Syntrophomonas wolfei. J Bacteriol 191(19):6167 6177

Müller N, Worm P, Schink B, Stams AJ, Plugge CM (2010) Syntrophic butyrate and propionate oxidation processes: from genomes to reac tion mechanisms. Environ Microbiol Rep 2(4):489 499

Müller V (2015) Microbial life at the thermodynamic limit: how much energy is required to sustain life? Environ Microbiol Rep 7(1):31 32

Nationale Akademie der Wissenschaften Leopoldina (2012) Bioenergie: Möglichkeiten und Grenzen. Halle (Saale) Online unter: http:// wwwleopoldinaorg/uploads/tx leopublication/ 201207 Empfehlungen_Bioenergie 02pdf

Noike T, Endo G, Chang JE, Yaguchi JI, Matsumoto JI (1985) Characteristics of carbohydrate degradation and the rate limiting step in anaerobic digestion. Biotechnol Bioeng 27(10):1482 1489

Palatsi J, Viñas M, Guivernau M, Fernandez B, Flotats X (2011) Anaerobic digestion of slaughterhouse waste: main process limita tions and microbial community interactions. Bioresour Technol 102(3):2219 2227

Pauss A, Samson R, Guiot S (1990) Thermodynamic evidence of trophic microniches in methanogenic granular sludge bed reactors. Appl Microbiol Biotechnol 33(1):88 92

Penning H, Conrad R (2006) Effect of inhibition of acetoclastic methanogenesis on growth of archaeal populations in an anoxic model environment. Appl Environ Microbiol 72(1):178 184

Ragsdale SW, Pierce E (2008) Acetogenesis and the Wood Ljungdahl pathway of $\mathrm{CO}_{2}$ fixation. Biochimica et Biophysica Acta (BBA) Proteins and Proteomics 1784(12):1873 1898

Schink B (1997) Energetics of syntrophic cooperation in methanogenic degradation. Microbiol Mol Biol Rev 61(2):262 280

Schink B, Stams AJ (2013) Syntrophism among prokaryotes. In: Rosenberg E, DeLong EF, Lory S, Stackebrandt E, Thompson F (eds) The prokaryotes prokaryotic communitites and ecophysiolo gy, 4th edn. Springer, Berlin Heidelberg, pp 471493

Schmidt A, Müller N, Schink B, Schleheck D (2013) A proteomic view at the biochemistry of syntrophic butyrate oxidation in Syntrophomonas wolfei. PLoS One 8(2):e56905

Schnürer A, Houwen FP, Svensson BH (1994) Mesophilic syntrophic acetate oxidation during methane formation by a triculture at high ammonium concentration. Arch Microbiol 162(1 2):70 74

Schnürer A, Schink B, Svensson BH (1996) Clostridium ultunense sp. nov., a mesophilic bacterium oxidizing acetate in syntrophic associ ation with a hydrogenotrophic methanogenic bacterium. Int J Syst Bacteriol 46(4):1145 1152

Schnürer A, Svensson BH, Schink B (1997) Enzyme activities in and energetics of acetate metabolism by the mesophilic syntrophically acetate oxidizing anaerobe Clostridium ultunense. FEMS Microbiol Lett 154(2):331 336

Scholten JC, Conrad R (2000) Energetics of syntrophic propionate oxi dation in defined batch and chemostat cocultures. Appl Environ Microbiol 66(7):2934 2942

Schuchmann K, Müller V (2014) Autotrophy at the thermodynamic limit of life: a model for energy conservation in acetogenic bacteria. Nat Rev Microbiol 12:809 821

Seiler W, Giehl H, Roggendorf P (1980) Detection of carbon monoxide and hydrogen by conversion of mercury oxide to mercury vapor. Atmos Technol, United States, p. 12

Seitz H J, Schink B, Pfennig N, Conrad R (1990) Energetics of syntrophic ethanol oxidation in defined chemostat cocultures. Arch Microbiol 155(1):82 88

Spahn S, Brandt K, Müller V (2015) A low phosphorylation potential in the acetogen Acetobacterium woodii reflects its lifestyle at the ther modynamic edge of life. Arch Microbiol 197:745 751

Thauer RK, Jungermann K, Decker K (1977) Energy conservation in chemotrophic anaerobic bacteria. Bacteriol Rev 41(1):100

Wang J, Liu H, Fu B, Xu K, Chen J (2013) Trophic link between syntrophic acetogens and homoacetogens during the anaerobic acidogenic fermentation of sewage sludge. Biochem Eng J 70: 18

Worm P, Fermoso FG, Stams AJ, Lens PN, Plugge CM (2011) Transcription of fdh and hyd in Syntrophobacter spp. and Methanospirillum spp. as a diagnostic tool for monitoring anaerobic sludge deprived of molybdenum, tungsten and selenium. Environ Microbiol 13(5):1228 1235

Zinder SH, Koch M (1984) Non aceticlastic methanogenesis from ace tate: acetate oxidation by a thermophilic syntrophic coculture. Arch Microbiol 138(3):263 272 